\title{
Bone Mineral Density of the Lumbar Spine in White Mediterranean Spanish Children and Adolescents: Changes Related to Age, Sex, and Puberty
}

\author{
L. Del RIO, A. CARRASCOSA, F. PONS, M. GUSINYÉ, D. YESTE, AND F. M. DOMENECH \\ CETIR [L.d.R., F.P., F.M.D.J and Children's Hospital Vall d' Hebron, Department of Pediatrics, Autonomous \\ University of Barcelona, Barcelona, Spain
}

\begin{abstract}
Bone mineral content was measured by dualenergy $x$-ray absorptiometry in the lumbar spine at the L2-LA level with a Lunar DPX densitometer model in 471 healthy white Mediterranean Spanish children and adolescents ( 256 boys and 215 girls) randomly selected from the urban area of Barcelona. Ages ranged from $3 \mathrm{mo}$ to $21 \mathrm{y}$. Weight, height, and pubertal development were in the normal age distribution. Bone mineral content values were corrected by the vertebral surface area scanned and expressed as bone mineral density (BMD) values. BMD increased progressively from infancy to adulthood, and values were similar in both sexes, with the only differences related to the earlier onset of puberty in girls. A statistically significant correlation $(p<0.001)$ was found between BMD values and age, height, and weight. BMD values increased annually, but the periods of higher increase were observed during the first 3 y of life and late puberty. A significant $(p<0.001)$ increase in BMD was observed between Tanner pubertal stages III and IV and between Tanner stage IV and adult values. Lumbar BMD values peaked in a similar way to growth height velocity during pubertal development. However, the BMD peak seemed to occur somewhat later than height velocity peak, particularly in girls. In conclusion, we report normative data for BMD values at the lumbar level in our normally growing pediatric population and show that the first $3 y$ of life and adolescence are critical periods for bone mineralization. These data provide a tool for the investigation and followup of pediatric populations at risk for low bone mineralization. (Pediatr Res 35: 362-366, 1994)
\end{abstract}

\section{Abbreviations}

BMC, bone mineral content (g hydroxyapatite) BMD, bone mineral density ( $\mathrm{g}$ hydroxyapatite $/ \mathrm{cm}^{2}$ )

Skeletal growth and mineralization develop through infancy, childhood, puberty, and adolescence, and several nutritional and hormonal factors play a major role in this process (1-8). Maximum BMC is attained by the age of $21 \mathrm{y}$ and decreases gradually after the age of 50, particularly in women (9). In addition, low $\mathrm{BMC}$ in adults is a risk factor for osteoporotic fractures later in life (10).

Received February 23, 1993; accepted October 11, 1993.

Correspondence and reprint requests: Prof. Antonio Carrascosa, Jefe Servicio Pediatria, Hospital Materno-infantil Vall d' Hebron, Paseo del Valle Hebron s/n, 08035 Barcelona, Spain.
Thus, the first 21 y of life are crucial for skeletal mineralization, and knowledge of normal values of this process in the pediatric population is of paramount importance. Furthermore, these normal values may vary from one geographic area to another and be influenced by genetic, racial, and nutritional factors (2$4,9,11-15)$.

In the last few years, several methods for measuring skeletal mineral content have become available, among which dualenergy $x$-ray absorptiometry is the least time consuming, most accurate, and most precise; it also is the safest because less radiation is absorbed (10). It is thus the method of choice in pediatric population studies. To date, only two studies of normal BMD values evaluated by dual-energy $x$-ray absorptiometry in the pediatric population have been published: one studied children 1 to $15 \mathrm{y}$ old (16), and the other studied children 1 to $19 \mathrm{y}$ old (17).

The aims of this work were as follows: 1) to evaluate BMD of the lumbar spine (L2-L4) with dual-energy $x$-ray absorptiometry in a normally growing white Mediterranean Spanish pediatric population from the Barcelona area; 2 ) to relate these values to age, sex, weight, height, and pubertal status; and 3) to compare these values with those previously reported for other normal pediatric populations.

\section{MATERIALS AND METHODS}

Subjects. The population studied consisted of 471 healthy white Mediterranean Spanish children and adolescents ( 256 boys and 215 girls) randomly selected from the urban area of Barcelona. Ages ranged from 3 mo to 21 y (Table 1). Weight and height were in the normal age distribution for our population. Pubertal status for genital stages in males and for breast development in females was assessed according to the criteria of Tanner (18). All subjects were receiving a standard Mediterranean diet according to age. The study was approved by our ethics committee, and informed consent was obtained from either the parents or the subjects.

Methods. Total BMC was measured by dual-energy x-ray absorptiometry in the lumbar spine at the L2-L4 level with a Lunar DPX-L densitometer model. This equipment has an $x-$ ray source emitting photon beams of $38 \mathrm{keV}$ and $70 \mathrm{keV}$ (9). Scanning time ranged from 3 to 8 min depending on the age of the child. The radiation dose at the skin level of the lumbar spine was less than $1 \mathrm{mrem}$, which represents a negligible gonadal dose (less than $0.25 \mathrm{mrem}$ in boys and less than $0.5 \mathrm{mrem}$ in girls).

Subjects were examined while they were in the supine decubitus position with partial elevation of the lower limbs to obtain optimum separation of the lumbar vertebrae, thus decreasing physiologic lordosis of this region. A special device was made to 
Table 1. BMD and BMC values of lumbar spine (L2-L4) in 471 normally growing children and adolescents (3 mo to 21 y) from the Barcelona area, (256 boys, 215 girls)*

\begin{tabular}{|c|c|c|c|c|c|c|c|c|c|c|}
\hline \multirow[b]{2}{*}{ Age group } & \multicolumn{5}{|c|}{ Boys } & \multicolumn{5}{|c|}{ Girls } \\
\hline & $n$ & $\begin{array}{c}\text { BMD } \\
\left(\mathrm{g} / \mathrm{cm}^{2}\right)\end{array}$ & $\mathrm{SD}$ & $\mathrm{BMC}^{*}$ & $\mathrm{SD}$ & $n$ & $\begin{array}{c}\text { BMD } \\
\left(\mathrm{g} / \mathrm{cm}^{2}\right)\end{array}$ & $\mathrm{SD}$ & $\mathrm{BMC}^{*}$ & $\mathrm{SD}$ \\
\hline $3 \mathrm{mo}$ & 1 & 0.157 & & 1.21 & & 2 & 0.208 & & 1.08 & \\
\hline $3 \mathrm{mo}-1 \mathrm{y}$ & 8 & 0.232 & 0.05 & 1.72 & 0.65 & 6 & 0.257 & 0.06 & 2.20 & 0.86 \\
\hline $1-2 y$ & 8 & 0.380 & 0.06 & 3.76 & 1.54 & 9 & 0.380 & 0.06 & 4.61 & 1.24 \\
\hline $2-3 y$ & 14 & 0.480 & 0.07 & 7.10 & 2.09 & 14 & 0.480 & 0.07 & 6.70 & 1.42 \\
\hline $3-4 y$ & 10 & 0.565 & 0.07 & 9.37 & 1.91 & 6 & 0.565 & 0.07 & 9.91 & 1.58 \\
\hline $4-5 y$ & 11 & 0.620 & 0.07 & 12.61 & 3.05 & 6 & 0.620 & 0.07 & 10.98 & 1.52 \\
\hline $5-6 y$ & 16 & 0.640 & 0.08 & 14.51 & 1.72 & 14 & 0.640 & 0.08 & 13.43 & 1.40 \\
\hline $6-7 y$ & 9 & 0.670 & 0.08 & 18.26 & 2.11 & 8 & 0.670 & 0.08 & 15.16 & 2.06 \\
\hline $7-8 y$ & 9 & 0.700 & 0.08 & 19.41 & 3.42 & 12 & 0.700 & 0.08 & 16.43 & 2.05 \\
\hline $8-9 y$ & 13 & 0.710 & 0.08 & 21.54 & 2.40 & 9 & 0.750 & 0.08 & 15.76 & 2.50 \\
\hline $9-10 y$ & 12 & 0.735 & 0.08 & 22.17 & 2.17 & 13 & 0.785 & 0.09 & 22.16 & 3.65 \\
\hline $10-11 y$ & 8 & 0.750 & 0.09 & 21.99 & 2.67 & 15 & 0.820 & 0.09 & 23.91 & 2.88 \\
\hline $11-12 y$ & 10 & 0.785 & 0.10 & 23.71 & 2.22 & 5 & 0.880 & 0.09 & 26.18 & 4.10 \\
\hline $12-13 y$ & 13 & 0.865 & 0.10 & 26.43 & 3.39 & 9 & 0.970 & 0.09 & 32.17 & 2.84 \\
\hline $13-14 y$ & 7 & 0.960 & 0.10 & 31.11 & 8.04 & 6 & 1.070 & 0.10 & 39.13 & 6.98 \\
\hline $14-15 y$ & 9 & 1.050 & 0.10 & 37.85 & 10.28 & 7 & 1.090 & 0.10 & 41.16 & 8.25 \\
\hline $15-16 y$ & 14 & 1.110 & 0.10 & 44.46 & 13.05 & 14 & 1.111 & 0.10 & 39.24 & 6.47 \\
\hline $16-17 y$ & 10 & 1.150 & 0.11 & 49.56 & 7.83 & 9 & 1.130 & 0.10 & 50.80 & 13.92 \\
\hline $17-18 y$ & 6 & 1.170 & 0.11 & 54.22 & 9.46 & 14 & 1.150 & 0.11 & 46.12 & 5.13 \\
\hline $18-19 y$ & 20 & 1.190 & 0.10 & 57.92 & 9.67 & 10 & 1.170 & 0.11 & 47.98 & 5.46 \\
\hline $19-20 y$ & 17 & 1.210 & 0.12 & 68.67 & 4.81 & 6 & 1.185 & 0.12 & 46.00 & 5.95 \\
\hline $21-21 y$ & 31 & 1.220 & 0.12 & 69.02 & 5.25 & 21 & 1.200 & 0.12 & 47.50 & 6.59 \\
\hline
\end{tabular}

* Measured in grams hydroxyapatite.

keep small, uncooperative children immobile. All the studies were performed with a constant pixel size of $1.2 \times 1.2 \mathrm{~mm}$. Bone edges and baseline determinations were operator-adjusted in children under 6 y of age. Lunar software programs (versions 3.4 and 3.5, Lunar Corp., Madison, WI) were used (9).

BMC values were corrected by the vertebral surface area scanned and expressed as BMD values. Values were grouped according to age and sex in 1-y age groups. The mean and SD were calculated, and the correlation index with height and weight was established.

BMD values were also evaluated five times in five 17 -y-old adolescents and three times in four 5- to 7 -y-old children. The mean and SD of these values were obtained, and the variation coefficient was calculated for each age group.

Statistics. Simple and polynomial regressions were carried out between BMD and the other variables. Correlations among the different variables were studied by the Pearson test. Differences among mean pubertal BMD values at different Tanner stages were performed by $t$ test.

\section{RESULTS}

Table 1 shows lumbar L2-L4 BMC values for boys and girls according to age. BMC values progressively increase from infancy to adulthood, and mean values are similar in both sexes until the age of 9-10 y, as occurs with height. Thereafter, and corresponding to the more rapid height growth rate observed in girls because of earlier pubertal development, BMC values are higher in girls than in boys until the age of 14-15 y. In boys, an increase rate in BMC values during pubertal development is also observed. Furthermore, BMC values continue to increase in both sexes even after adult height is attained: $15-16 \mathrm{y}$ of age in girls and 17-18 y in boys until the age of $21 \mathrm{y}$. Adult BMC values are higher in boys than in girls, as occurs with height. A statistically significant positive correlation $(p<0.001)$ was found in both sexes between BMC values and age, height, and weight (data not shown).

Table 1 and Figure 1 show lumbar BMD values for boys and girls according to age. Results are expressed as mean \pm 1 SD. A progressive increase in BMD occurs from infancy to adulthood. Mean BMD values are similar at the same age in both sexes, with the only differences related to the earlier onset of puberty in girls. The value of $1 \mathrm{SD}$ increases with age in a similar way in both sexes. However, if the value of $1 \mathrm{SD}$ is expressed as a percentage of the value of the mean in each age group, for children older than $3 \mathrm{y}$ it represents a constant value, which is on average $11 \%$ of the value of the mean. In children under $3 y$ of age, the value of $1 \mathrm{SD}$ ranges from $15 \%$ to $21 \%$ of the value of the mean and is higher during the 1st y of life (Table 1). The best graphic representation of BMD values according to age corresponds to a 3 rd-degree polynomial equation $(\mathrm{y}=0.31+$ $0.063 \times-0.0008 \times 2-5.75 \times 3$ ).

Table 2 shows BMD values according to pubertal development. A significant increase was observed during puberty, being higher between Tanner's stages III and IV.

Figure 2 shows the annual increment in BMD values for boys and girls. These values increase annually from infancy to adulthood, with the periods of highest increase occurring in the first $3 \mathrm{y}$ of life and late puberty. A slow rate increase was observed in the prepubertal period and from Tanner's stage IV to adulthood.

A statistically significant positive correlation was found between BMD values and age $(r=0.92$ in boys, and $r=0.94$ in girls, $p<0.001)$, height $(r=0.91$ in boys, and $r=0.93$ in girls, $p<0.001$ ), and weight ( $r=0.92$ in boys, and $r=0.93$ in girls, $p$ $<0.001$ ). The coefficient of variation for BMD values was $1.6 \%$ and $0.8 \%$ for the child and adolescent groups, respectively.

\section{DISCUSSION}

The rate of bone turnover is known to be much more rapid in trabecular than in cortical bones. Furthermore, trabecular bone appears to be more sensitive to mineral changes than the cortical (19). Thus, we studied changes in bone mineralization by dualenergy $\mathrm{x}$-ray absorptiometry at the lumbar spine L2-L4 level, which is composed mainly of trabecular bone, and related these changes to age, sex, and pubertal development. 

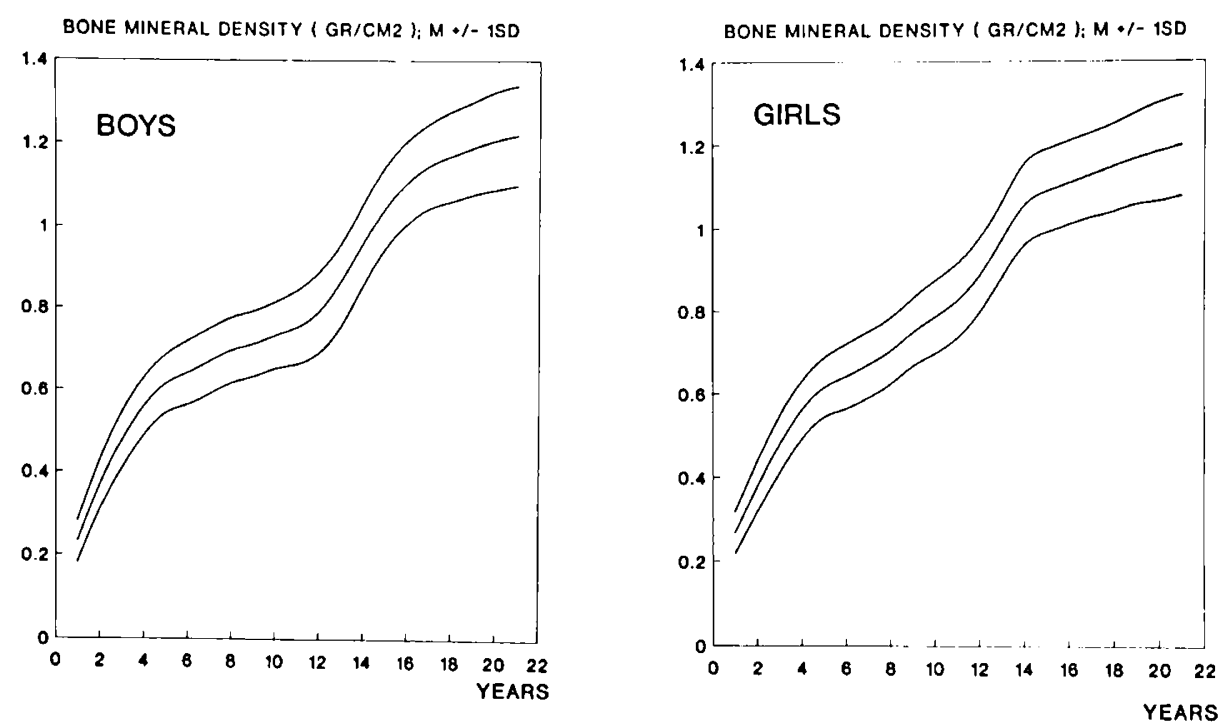

Fig. 1. Mean $\pm 1 \mathrm{SD}$ values $\left(\mathrm{g} / \mathrm{cm}^{2}\right)$ of $\mathrm{BMD}$ values in the lumbar spine (L2-L4) in a normally growing pediatric population from infancy to adulthood.

Table 2. Changes in pubertal L2-L4 BMD values $\left(\mathrm{g} / \mathrm{cm}^{2}\right)$ in boys and girls according to Tanner's stages

\begin{tabular}{|c|c|c|c|c|c|c|}
\hline \multirow{2}{*}{$\begin{array}{c}\text { Tanner } \\
\text { pubertal } \\
\text { stage }\end{array}$} & \multicolumn{3}{|c|}{ Boys } & \multicolumn{3}{|c|}{ Girls } \\
\hline & $n$ & Mean* & SD & $n$ & Mean $\dagger$ & SD \\
\hline II & 7 & 0.740 & 0.03 & 6 & 0.784 & 0.03 \\
\hline III & 7 & 0.802 & 0.06 & 7 & 0.831 & 0.07 \\
\hline IV & 7 & 1.020 & 0.09 & 7 & 1.029 & 0.14 \\
\hline Adults & 31 & 1.220 & 0.12 & 21 & 1.200 & 0.12 \\
\hline
\end{tabular}

* Stage III $v s$ stage II, $p=0.03$; stage IV $v s$ stage III, $p<0.001$; adults vs stage IV, $p<0.001$.

† Stage III $v$ stage II, NS; stage IV vs stage III, $p<0.001$; adults $v s$ stage IV, $p<0.001$.

Total bone mineral vertebral content not only depends on the amount of mineral deposits in bone matrix but also on vertebral size and consequently on the height of the subject studied. In growing pediatric populations, the best way to express changes in bone mineralization is to correct total BMC by the vertebral

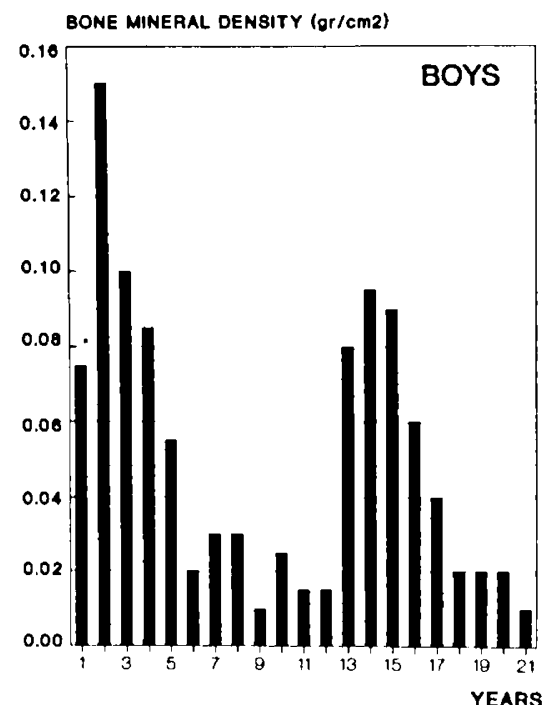

volume. However, calculation of this volume is difficult and imprecise [although attempts to improve it are currently being made (20)]. For these reasons, total BMC values obtained in our normally growing pediatric population were corrected by the area surface scanned and expressed as BMD values because this method better reflected bone matrix mineralization changes in subjects with different heights. BMC values are similar in both sexes when heights are similar during the prepubertal growth period and differ when heights are different during pubertal growth and adult periods. However, BMD values only differ between boys and girls in relationship to the earlier onset of puberty in girls, but BMD values do not differ between the sexes when these pubertal values are related to Tanner's developmental pubertal stages because these stages represent similar maturation periods in both sexes. These data show that in a pediatric growing population, BMC values are related more to height than BMD values and that $B M D$ values may reflect better bone matrix mineralization than BMC values. Thus, BMD values permit better comparison of bone matrix mineralization changes from infancy to adulthood.

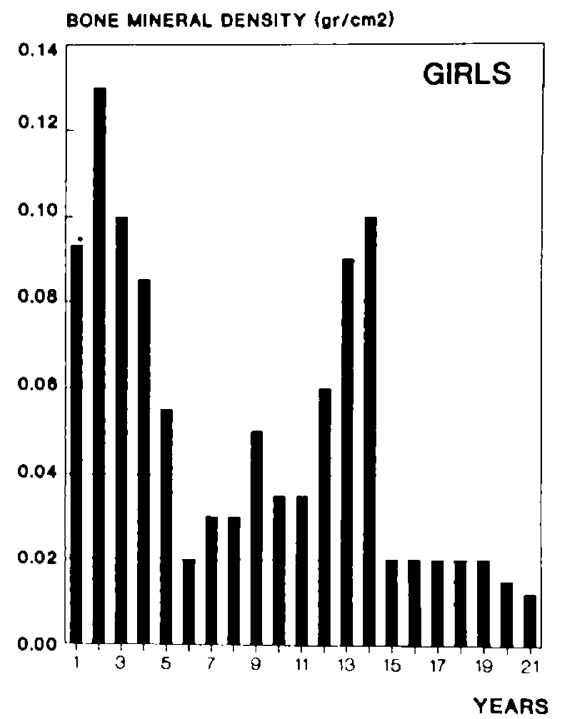

Fig. 2. Annual increase in BMD values $\left(\mathrm{g} / \mathrm{cm}^{2}\right)$ evaluated in the lumbar spine (L2-L4) in a normally growing pediatric population from infancy to adulthood. *, Difference in values between 1 y and 3 mo of age. 
Previously published studies of BMD values evaluated by dualenergy $\mathrm{x}$-ray absorptiometry in children were performed with technical equipment different from that used by us. Furthermore, differences in lumbar BMD have been shown with different technical equipment, and equivalent conversion values are thus required (21). In the present study we report normative data for BMD values evaluated by the Lunar DPX-L densitometer. In addition, none of the previously published series were as extensive as ours, and in one of these studies, only data up to the age of 15 y were reported $(16,17)$.

In our normal pediatric population, BMD of the lumbar spine increases continuously from infancy to adulthood and is correlated with age, height, and weight. These data are in agreement with those previously reported using different methodologies (16, $17,20-27)$. The coefficient of variation of the values obtained with our method in adolescents is similar to that found in adults (9) and somewhat higher in children 5-7 y old. For ethical reasons, precision studies were not performed in infants and young children. However, in children older than $7 \mathrm{y}$, precision values may be assumed to be similar to those of adolescents because the value of 1 SD expressed as a percentage of the value of the mean is similar in all those 1-y age groups. In children younger than $3 \mathrm{y}$, the value of $1 \mathrm{SD}$ expressed as a percentage of the value of the mean is higher than in children older than $3 \mathrm{y}$. Low bone vertebral mineralization, together with the greatly increased mineralization rate (see below) and the small vertebral size observed during the first 3 y of life, may account for this difference. Studies that involved more children grouped in time periods of less than 1 y (e.g. 6-mo periods) would be required to establish the normal vertebral mineralization pattern in this population, as occurs in neonates $(28,29)$.

The annual increment in BMD values is high during the first $3 \mathrm{y}$ of life and decreases thereafter until puberty, as occurs with height growth velocity. During puberty an increase also occurs in BMD values, which peaks in late puberty, corresponding to Tanner's stage IV, and continues at a slow rate to adulthood. This peak seems to occur later than the growth velocity peak, particularly in girls (18). These data are from a cross-sectional study, and data from longitudinal studies of the same population are required to clarify the relationship between the ages at which pubertal height growth and pubertal BMD peaks occur. Our data concur with those previously reported $(16,17,20,27)$ and show adolescence to be a critical period for bone mineralization in both sexes.

It has been shown recently that sex steroids have receptors and exert biologic effects on both epiphyseal cartilage cells (30-32) and bone cells $(33,34)$ and that these hormones play an important role in skeletal growth and mineralization. Our results show that the skeletal mineralization rate during puberty is related to the Tanner pubertal stages and suggest that low steroid levels of Tanner pubertal stages II and III may be involved more in promoting linear skeletal growth than in skeletal mineralization and that high steroid levels observed in Tanner stage IV and thereafter may be mainly involved in promoting skeletal mineralization.

In conclusion, lumbar BMD was studied by dual-energy $\mathrm{x}$-ray absorptiometry in a normally growing white pediatric population from the Mediterranean area, and normal distribution values were established. BMD increases with age and is related to weight, height, and pubertal changes. These data provide an excellent tool for the earlier detection and follow-up of pediatric populations at risk for low bone mineralization and consequently for adult osteoporotic risk fractures. Our data also stress the importance of the first $3 \mathrm{y}$ of life and adolescence as critical periods for bone mineralization.

Acknowledgment. The authors thank C. O'Hara for useful manuscript corrections.

\section{REFERENCES}

1. Kreipe RE, Forges GB 1990 Osteoporosis: a "new morbidity" for dicting female adolescents. Pediatrics $89: 478-480$

2. Chan GM 1991 Dietary calcium and bone mineral status of children and adolescents. Am J Dis Child 145:631-634

3. Sentipal JM, Wardlaw GM, Mahan J, Matkovic V 1991 Influence of calcium intake and growth indexes on vertebral bone mineral density in young females. Am J Clin Nutr 54:425-428

4. Johnston Jr CC, Miler JZ, Slemenda CW 1992 Calcium supplementation and increases in bone mineral density in children. N Engl J Med 327:82-87

5. Lindsay R, Hart DM, Aitken JM, MacDonald EB, Anderson JB, Clarke AC 1976 Long-term prevention of postmenopausal osteoporosis by ocstrogen. Lancet 1:1038-1041

6. Gennari C 1985 Glucocorticosteroids and bone. In: Peck WA (ed) Bone and Mineral Research/3. Elsevier Amsterdam, pp 213-231

7. Kaufman JM, Taelman P, Vermeulen A, Vandeweghe M 1992 Bone mineral status in growth hormone-deficient males with isolated and multiple pituitary deficiencies of childhood onset. J Clin Endocrinol Metab 74:118-123

8. Finkelstein JS, Neer RM, Beverly MK, Crawford JD, Klibanski A 1992 Osteopenia in men with a history of delayed puberty. N Engl J Med 326:600604

9. del Rio L, Romera M, Pavia J, Setoain J, Serra L, Garces P, Lafuente C, Domenech F 1992 Bone mineral density in two different socio-economic population groups. Bone Miner 18:159-168

10. Johnston GC, Slemenda ChW, Melton LJ 1991 Clinical use of bone densitometry. N Engl J Med 324:1105-1109

11. Pollitzer WS, Anderson JJ 1989 Ethnic and genetic differences in bone mass: a review with a hereditary is environmental perspective. Am J Clin Nutr 50:1244-1259

12. Reid IR, Mackie M, Ibbertson HK 1986 Bone mineral content in Polynesian and white New Zealand women. BMJ 292:1547-1548

13. Garn SM, Pao EM, Rihl ME 1964 Compact bone in Chinese and Japanese. Science 143:1439-1440

14. Li JY, Specker BL, Ho ML, Tsang RC 1989 Bone mineral content in black and white children 1 to 6 years of age: early appearance of race and sex differences. Am J Dis Child 143:1346-1349

15. Gilsanz V, Roe ThF, Mora S, Costin G, Goodman WG 1991 Changes in vertebral bone density in black girls and white girls during childhood and puberty. N Engl J Med 325:1597-1600

16. Glastre C, Braillon P, David L, Cochat P, Meunier PJ, Delmas PD 1990 Measurement of bone mineral content of the lumbar spine by dual-energy $\mathrm{x}$-ray absorptiometry in normal children: correlations with growth parameters. J Clin Endocrinol Metab 70:1330-1333

17. Southard RN, Morris JD, Mahan JD, Hayes JR, Torch MA, Sommer A, Zipf W 1991 Bone mass in healthy children: measurement with quantitative DXA. Radiology 179:735-738

18. Tanner JM 1962 Growth at Adolescence. Blackwell Scientific Publications, Philadelphia

19. Seeman E, Wahner HW, Offord KP, Kuman P, Johnson WJ, Riggs BL 1982 Differential effects of endocrine dysfunction on the axial and the appendicular skeleton. J Clin Invest 29:1302-1309

20. Katzman DH, Bachrach LK, Carter DR. Marcus R 1991 Clinical and anthropometic correlates of bone mineral acquisition in healthy adolescent girls. $J$ Clin Endocrinol Metab 73:1333-1339

21. Vainio P, Ahonen E, Leiononen K, Seivänen H, Kosku E 1992 Comparison of instruments for dual-energy $x$-ray bone mineral densitometry. Nucl Med Commum 13:252-255

22. Landin L, Nilson BE 1981 Forearm bone mineral content in children. Acta Paediatr Scand 70:919-923

23. Specker BL, Brazerol W, Tsang RC, Levin R, Searcy J, Steichen J 1987 Bone mineral content in children 1 to 6 years of age. Am J Dis Child 141:343344

24. Barden HS, Mazess RB 1988 Bone densitometry in infants. J Pediatr 113:172177

25. Ponder SW, McCormick DP, Fawcett HD, Palmer JL, McKerman MG, Brouhard BH 1990 Spinal bone mineral density in children aged 5.00 through 11.99 years. Am J Dis Child 144:1346-1348

26. De Schepper J, Dede MP, Van den Broeck M, Piepsz A, Jonckherr MH 1991 Normative data for lumbar spine bone mineral content in children: influence of age, height, weight, and pubertal stage. J Nucl Med 32:216-220

27. Lloyd T, Rollings N, Andon MB, Demers LM, Eggli DF, Kieselhorst K, Kulin H, Landis JR, Martel JK, Orr G, Smith Ph 1992 Determinants of bone density in young women. I. Relationships among pubertal development, total body bone mass, and total body bone density in premenarcheal females. J Clin Endocrinol Metab 75:383-387

28. Horsman A, Ryan SW, Congdon PJ, Truscott JG, Simpson M 1989 Bone mineral content and body size 65 to 100 weeks postconception in preterm and full term infants. Arch Dis Child 64:1579-1586

29. Braillon PM, Salle BL, Brunet J, Glorieux FH, Delmas PD, Meunier PJ 1992 
Dual energy $x$-ray absorptiometry measurement of bone mineral content in newborns: validation of the technique. Pediatr Res 32:77-80

30. Audi L, Carrascosa A, Ballabriga A 1984 Androgen metabolism by human epiphyseal cartilage and its chondrocytes in primary culture. J Clin Endocrinol Metab 58:819-825

31. Corvol MT, Carrascosa A, Tsagris L, Rappaport R 1987 Evidence for a direct in vitro action of sex steroids on rabbit cartilage cells during skeletal growth: infuence of age and sex. Endocrinology 120:1422-1429

32. Carrascosa A, Audi L, Ferrandez MA, Ballabriga A 1990 Biological effects of androgens and identification of specific dihydrotestosterone-binding sites in cultured human fetal epiphyseal chondrocytes. J Clin Endocrinol Metab 70:134-140

33. Ernst M, Schmid C, Froesch ER 1988 Enhanced osteoblast proliferation and collagen gene expression by estradiol. Proc Natl Acad Sci USA 85:23072310

34. Kasperk Ch, Fitzsimmons R, Strong D, Mohan S, Jennings J, Wergedal J, Baylink D 1990 Studies of the mechanism by which androgens enhance mitogenesis and differentiation in bone cells. J Clin Endocrinol Metab $71: 1322-1329$

\section{Announcement}

\section{Research on Hair Testing for Drugs of Abuse}

The National Institute on Drug Abuse has an interest in research on the utility of hair as a specimen for the detection of drugs of abuse. The goals of this program are to encourage systematic research on the use of hair testing to detect drugs of abuse in an accurate and reliable manner and to develop the necessary procedures and safeguards. Specific areas of interest are pharmacologic studies, analytical studies, and cost/benefit ratio analyses. Further information may be obtained from Rao S. Rapaka, Ph.D., or M. Beth Grigson Babecki, M.A., Division of Basic Research, National Institute on Drug Abuse, 5600 Fishers Lane, Room 10A-31, Rockville, MD 20857, (301) 443-6975. (Program announcement no. PA-92-18, November 1, 1991-November 1, 1994) 